\title{
Tüm Üç Hücreli Biyolojik Sinir Ağı Motiflerinin Kısa- ve Uzun Dönem Bellek Davranışının İncelenmesi
}

\author{
Ahmet TURAN $^{1 *}$ (D), Temel KAYIKÇIOĞLU² \\ 1 Elektrik ve Elektronik Mühendisliği Bölümü, Kastamonu Üniversitesi, Kastamonu, Türkiye \\ 2 Elektrik ve Elektronik Mühendisliği Bölümü, Karadeniz Teknik Üniversitesi, Trabzon, Türkiye
}

Geliş / Received: 21/05/2018, Kabul / Accepted: 13/05/2019

\begin{abstract}
$\ddot{\mathbf{O z}}$
Bellek ve öğrenme ile ilgili önemli biyolojik çalışmalar yapılmaktadır. Beyin hücrelerinin, çözelti ve canlı doku ortamlarında incelenmesi ve ayrıca elektron mikroskopla görüntü çalışmaları, önemli bulgular ortaya koymuştur. Elde edilen biyolojik veriler, beyinde çok sayıda sinir hücresinin, karmaşık bağlantılar oluşturduğunu göstermiştir. Bu büyük biyolojik sinir ağ1 yapısında; tekrarlanan ve motif olarak isimlendirilen bölümler gözlenmiştir. Bu motiflerin, biyolojik sinir ağlarının temel yapı blokları olduğuna ve ağda önemli fonksiyonel roller oynadığına inanılmaktadır. Beyindeki bu sinir ağının bellek davranışını anlamak için, motiflerin davranışlarını bilmek gerektiği düşünülmektedir. Bu deneysel veriler yardımıyla, motifler hesapsal yöntemlerle modellenmiştir. Modeller üzerinde yapılan çalışmalardan; motiflerin biyolojik bellek davranışları incelenmektedir. Bu çalışmada tüm üç hücreli sinir ağı motiflerinin kısa- ve uzun dönem bellek fonksiyonları incelendi. Motifler, graph teorisi kullanılarak oluşturuldu. Motifleri oluşturan sinir hücreleri, Hodkgin-Huxley model kullanılarak, hücrenin soma kısmında, tek bölme şeklinde modellendi. Ayrıca hücreler arası bağlantı, kimyasal sinaps şeklinde modellendi. Oluşturulan tüm üç hücreli motif modelleri, Matlab yazılım ortamında geliştirildi. Modeller üzerinde yapılan çalışmalarda elde edilen sonuçlardan, üç hücreli motiflerin kısa -ve uzun dönem bellek davranışı gösterme durumları belirlendi. Çalışmanın sonunda, üç hücreli motiflerden kısa -ve uzun dönem bellek davranışı sergileyenler tespit edildi.
\end{abstract}

Anahtar Kelimeler: Biyolojik ağ, motif, hodkgin-huxley hücre modeli, kısa-dönem bellek, uzun-dönem bellek

\section{Research to Short- and Long Term Memory Effects of Three Nerve Cell Motif Based Neuronal Networks}

\begin{abstract}
There are important biological studies on memory and learning. Examination of brain cells in solution and living tissue media and also image studies with electron microscope revealed important findings. The obtained biological data showed that many nerve cells in the brain formed complex connections. In this great biological neural network structure; repeated and motif-named sections were observed. These motifs are believed to be the building blocks of biological neural networks and play important functional roles in the network. It is thought that in order to understand the memory behavior of this nerve network in the brain, it is necessary to know the behavior of the motifs. With the help of these experimental data, the motifs are modeled by computational methods. From studies done on models; biological memory behaviors of motifs are examined. In this study, short- and long-term memory functions of all three-cell neural network motifs were examined. Motives were created using graph theory. The nerve cells forming the motifs were modeled in the soma part of the cell using a Hodkgin-Huxley model as a single chamber. In addition, the intercellular connection was modeled as a chemical synapse. All three-celled motif models were developed in the Matlab software environment. The results of the studies on the models showed that the three-cell motifs showed short-term and long-term memory behavior. At the end of the study, short-term and long-term memory behavior of three-cell motifs were determined.
\end{abstract}

Keywords: Biological network, motif, hodgkin-huxley cell model, short-term memory, long-term memory 


\section{Giriş}

A $\breve{g}$ terimi; kendi aralarında bağlantı veya etkileşim olan bir takım elemanlar için yapılan bir tanımlamadır. Ağlar; biçimsel analizleri için, çizge olarak isimlendirilen grafiklerle modellenmiştir (Junker and Schreiber, 2008). Dinamik sistemlerin grafiksel olarak temsili olan ağ haritaları, biyolojik sistemlerin karışık yapılarını analiz etmek için kullanılan önemli bir yöntemdir. "Ağ motif” terimi yönlendirilmiş alt grafikleri gösterir. Birkaç düğümden meydana gelir ve büyük yönlendirilmiş çizgelerin içine gömülmüştür (Prill et al., 2005). Biyolojik verilerin analizleri için matematiksel ve hesapsal metotların uygulanmasi; sistemlerin karmaşıklığı ve verilerin bolluğu dolayısıyla oldukça önemlidir (Li, 2008). Biyolojik sinir ağ yapılarını tanımlamak için, deneysel ortamlarda bazı canlıların, beyin sinir hücrelerinin bağlantı haritaları çıkartılmıştır (Sporns and Kotter, 2004; Prill et al., 2005; Song et al., 2005; Li, 2008; Cornelia and Eve, 2013; Humphries, 2017; Meng and Xiang, 2018). Sinir ağları, ağ motifi olarak tanımlanan ve ağda çokça görülen özel fonksiyonlu alt ağ'lardan meydana gelir (Sporns and Kotter 2004; Song et al., 2005; Kim et al., 2008; Li, 2008; Dong et al., 2009; Heinz and Stefan 2009; Cornelia and Eve 2013). Biyolojik ağlardaki bellek sistemlerinin, temelde bellek yeteneğine sahip motifleri içerdiği düşüncesinden, motiflerin fonksiyonlarının anlaşılması, tüm ağların davranışlarının anlaşılması için bir adımdır (Kaiser and Peters 2009).

Literatürde yapılmış olan çalışmalarda genellikle, sınırlı sayıda motif incelenmiştir. $\mathrm{Bu}$ çalışmaların bazılarında motiflerin oluşumunda, iki giriş $(A, B)$ ve tek çıkış $(C)$ hücresi düşünülmüştür. Harici akım uygulaması A hücresine yapılırken bazen de eşik altı uyarımları destekleyecek şekilde B hücresine giriş yapılmıştır. (Sporns and Kotter, 2004; Milo et al., 2002). Çalışmamızda, motifleri oluşturan hücrelerin rolleri, A-giriş, B-ara ve C-çıkış olacak şekilde alındı ve tüm üç hücreli motifler, çizge topolojisi kullanılarak oluşturuldu. Böylece çalışmamızda daha fazla motifi değerlendirdik. Tablo 2'de görülen ve biyolojik sinir ağlarında görüntülenmiş üç hücreli ağ motiflerinin tümü, hücreler arası uyarım türünün (uyarıcı-engelleyici) motif yapısına göre tüm olasılıkları oluşturularak çalış1ldı. Ayrıca literatürdeki çalışmalarda, ağı oluşturan hücreler daha basit bir yöntem olan, topla ve ateşle yöntemiyle modellenmiştir. Hücreler arası uyarım şekli de, hücreye gürültü ilavesi şeklinde uygulanmıştır (Li, 2008). Çalışmamızda ise motifi oluşturan hücreler için, daha gerçekçi bir yaklaşım olan Hodgkin-Huxley modeli tercih edildi. Hücreler arası uyarım şekli de kimyasal sinaps şeklinde modellendi.

Çalışmamızda ilk olarak, motif yapılarında görülen temel bağlantıların uyarımlara cevabı incelendi. Ardından, birden çok uyarım alan hücrelerin, uyarım türlerinin farklılığ 1 durumundaki davranışları çalışıldı. Bunlardan elde edilen bulgular doğrultusunda, üç hücreli tüm bağlantı şekillerinin içerildiği motifler çalış1d1. Özellikle hücrelerin uyarım türlerinin (E,I) farklı olasılıklarında motiflerin kısa- ve uzun dönem bellek davranışları incelendi. Hedefimiz, üç hücreli motiflerin, kısa- ve uzun dönem bellek davranışı gösterdikleri tüm durumları belirlemektir. Bu çalışma; hücre rolleri dikkate alınarak, tüm üç hücreli motiflerin, yapı ve uyarım türü değişimlerinde, kısa-ve uzun dönem bellek davranışlarının incelendiği, kapsamlı bir çalışma olması yönü ile literatüre katkı sağlamıştır. (Bu konuda çalışmamızın sınırlı bir bölümü 2014 yılında sempozyum bildirisi olarak yayınlanmıştır .)

\section{Materyal ve Metot}

\subsection{Hücre ve ăg motiflerinin modellenmesi}

Çalışmamızda motifleri oluşturan hücreler, Hodgkin-Huxley'in deneysel çalışmalarından elde edilen ve hücrenin soma kısmina ait, deterministic tek bölme şeklinde modellendi (Schachinger 2003; Wang et al., 2005; Dayan and Abbott 2002; Izhikevich 2007). Hücreler 
arası iletişim, kimyasal sinaptik iletkenlik fonksiyonu ile modellenerek, güçlü bağlantı tercih edildi. Sinaptik denge potansiyeli, uyarımın etkisini belirleyecek şekilde, uyarıcı(E) ve engelleyici (I) olacak şekilde gerçekçi modellendi (Bower and Beeman,
1998; Gerstner and Kistler, 2002; Keener and Sneyd 2009; Jackman and Regehr, 2017; Navlakha et al., 2018 ). Şekil 1(a)'da görülen elektrik devresiyle modellenmiş hücreye ait çözümler ve parametre detayları denklem 117'de verilmiştir (Dayan and Abbott 2002).

$C_{m} \frac{d V_{m}}{d t}=-G_{L}\left(V_{m}-E_{L}\right)-\bar{G}_{N a} m^{3} h\left(V_{m}-E_{N a}\right)-\bar{G}_{K} n^{4}\left(V_{m}-E_{K}\right)+I_{u y g}(t)$

$\frac{d m}{d t}=\alpha_{m}\left(V_{m}\right)(1-m)+\beta_{m}\left(V_{m}\right) m$

$\frac{d h}{d t}=\alpha_{h}\left(V_{m}\right)(1-h)+\beta_{h}\left(V_{m}\right) h$

$\frac{d n}{d t}=\alpha_{n}\left(V_{m}\right)(1-n)+\beta_{n}\left(V_{m}\right) n$

$G_{N a}=\bar{G}_{N a} m^{3} h$

$G_{K}=\bar{G}_{K} n^{4}$

Denklemlerde, $V_{m}$ hücre zar gerilimi, $V_{r}$ ise dinlenme durumunda hücre zar gerilimidir. $\bar{G}_{N a}, \bar{G}_{K}$, hücre zarında bulunan sodyum $\left(\mathrm{Na}^{+}\right)$ve potasyum $\left(\mathrm{K}^{+}\right)$kanallarının maksimum iletkenlik değerleri, $G_{L}$ sizıntı akım iletkenliğidir. Modelde, $\mathrm{Na}^{+}$iyon kanalı, üç özdeş aktivasyon $\left(\mathrm{m}^{3}\right)$ ve bir inaktivasyon kapısı $(h)$ ve $K^{+}$iyon kanalı dört özdeş aktivasyon $\left(n^{4}\right)$ kapısı ile tanımlanmıştır. Bir kanalın açık ve kapalı durumlar arasındaki geçişleri, $\alpha\left(V_{m}\right)$ ve $\beta\left(V_{m}\right)$ gerilim bağımlı oran sabitleri ile tanımlanır. $\mathrm{Na}^{+}$akımının kararl1-durum aktivasyonu $m_{\infty}$, inaktivasyonu $h_{\infty} . K^{+}$akımının kararl1-durum aktivasyonu $n_{\infty}$ olarak tanımlidir. Denklem1'de $m, n, h$ yerine bu değerler kullanılmıştır (Bower and Beeman 1998). Sinaptik uyarı geldiğinde açılan transmitter-aktivasyonlu iyon kanalları, zaman bağımlı $g \operatorname{syn}(t)$ iletkenliği ile denklem 18'deki gibi tanımlanmıştır. Ayrıca sinaptik bağlantının akım ifadesi ve birden fazla uyarı alan hücrelerin çözümü, denklem 19 ve 20'de gösterildi (Bower and Beeman 1998).

$$
\begin{aligned}
& \boldsymbol{\alpha}_{\boldsymbol{m}}=\frac{-\mathbf{0 . 1}\left(\boldsymbol{V}_{\boldsymbol{m}}-\boldsymbol{V}_{\boldsymbol{r}}-\mathbf{2 5}\right)}{\exp \left[-\left(\boldsymbol{V}_{\boldsymbol{m}}-V_{\boldsymbol{r}}-\mathbf{2 5}\right) / \mathbf{1 0}\right]-\mathbf{1}} \quad \boldsymbol{V}_{\boldsymbol{r}}-\boldsymbol{V}_{\boldsymbol{m}}>\mathbf{2 4 . 9 9} \quad \text { ise } \\
& \alpha_{m}=\frac{-1}{\exp \left[-\left(V_{m}-V_{r}-25\right) / 10\right]} \quad V_{r}-V_{m} \leq 24.99 \quad \text { ise } \\
& \beta_{m}=4\left(\exp \left[-\left(V_{m}-V_{r}\right) / 18\right]\right) \\
& \alpha_{h}=0.07\left(\exp \left[-\left(V_{m}-V_{r}\right) / 20\right]\right) \\
& \beta_{h}=\frac{1}{1+\exp \left[-\left(V_{m}-V_{r}-30\right) / 10\right]} \\
& \alpha_{n}=\frac{0.01\left(V_{m}-V_{r}-10\right)}{1+\exp \left[-\left(V_{m}-V_{r}-10\right) / 10\right]} \quad V_{r}-V_{m}>9.99 \text { ise }
\end{aligned}
$$




$$
\begin{aligned}
& \alpha_{n}=\frac{0.1}{\exp \left[-\left(V_{m}-V_{r}-10\right) / 10\right]} \quad V_{r}-V_{m} \leq 9.99 \text { ise } \\
& \beta_{n}=0.125\left(\exp \left[-\left(V_{m}-V_{r}\right) / 80\right]\right) \\
& m_{\infty}\left(V_{m}\right)=\alpha_{m}\left(V_{m}\right) /\left(\alpha_{m}\left(V_{m}\right)+\beta_{m}\left(V_{m}\right)\right) \\
& h_{\infty}\left(V_{m}\right)=\alpha_{h}\left(V_{m}\right) /\left(\alpha_{h}\left(V_{m}\right)+\beta_{h}\left(V_{m}\right)\right) \\
& n_{\infty}\left(V_{m}\right)=\alpha_{n}\left(V_{m}\right) /\left(\alpha_{n}\left(V_{m}\right)+\beta_{n}\left(V_{m}\right)\right) \\
& g s y n(t)=g_{\max } \frac{t}{\tau} e^{\left(1-\frac{t}{\tau}\right)} \\
& I_{s y n}(t)=g_{s y n}(t)\left(V_{m}-E_{s y n}\right) \\
& C_{m} \frac{d V_{m}}{d t}+g_{\text {rest }} V_{m}+g_{s y n}{ }^{(1)}(t)\left(V_{m}-E_{\text {syn }}{ }^{(1)}\right)+g_{s y n}{ }^{(2)}(t)\left(V_{m}-E_{s y n}{ }^{(2)}\right)+\ldots=0
\end{aligned}
$$

Denklemlerde $E_{N a}, E_{K}, E_{L}$ iyon kanalı denge $\quad C_{m}=1 \mu F / \mathrm{cm}^{2}, \quad V_{r}=-65 \mathrm{mV}, \quad$ sinaptik potansiyelleri olup, deney ortamlarında $\mathrm{T}=$ denge potansiyelleri; engelleyici (I) $6.3^{\circ} \mathrm{C}$ için Nernst bağıntısıyla, hücre içi ve dışı $\quad E_{\text {syn }}=-70 \mathrm{mV}, \quad$ uyarıcı $\quad$ (E) iyon konsantrasyon değerleri için hesaplan- $E_{\text {syn }}=-10 \mathrm{mV}$, maksimum sinaptik mıştır (Gerstner and Kistler 2002). Hücrenin iletkenlik $g_{\max }=64 n S$, sinaptik iletkenlik soma kısmında, hücre zarının bir parçacı̆̆ına zaman sabiti $\tau=25 \mathrm{~ms}$ şeklinde kullanıldı. ait biyolojik çalış̧malardan elde edilen ve (Bower and Beeman 1998; Gerstner and Hodgkin-Huxley modelinde yaygın bir Kistler, 2002; Wang et al., 2005). Hücrelerin şekilde kullanılan parametre değerleri; elektriksel modeli, şekil 1'de gösterildiği gibi, $\bar{G}_{N a}=120 \mathrm{mS} / \mathrm{cm}^{2}, \quad \bar{G}_{K}=36 \mathrm{mS} / \mathrm{cm}^{2}, \quad$ aldığı uyarı türüne göre değişiklik $G_{L}=0.3 \mathrm{mS} / \mathrm{cm}^{2}, \quad E_{N a}=50 \mathrm{mV}, \quad$ göstermektedir. $E_{K}=-77 \mathrm{mV}, \quad E_{L}=-54.4 \mathrm{mV}$,

(a)

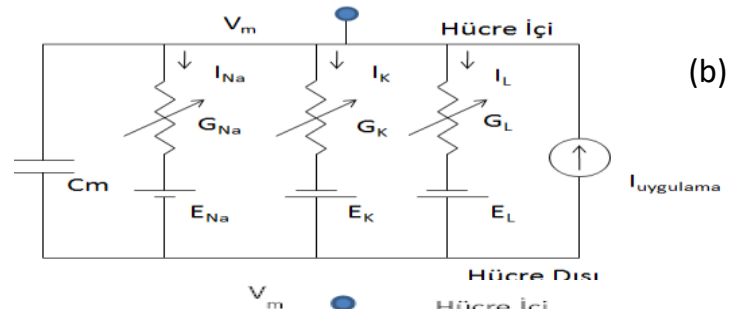

(c)

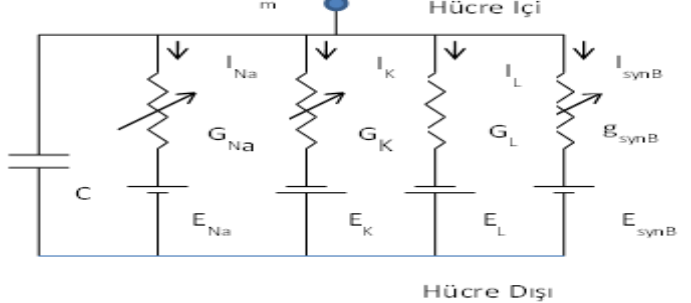

(b)

(d)
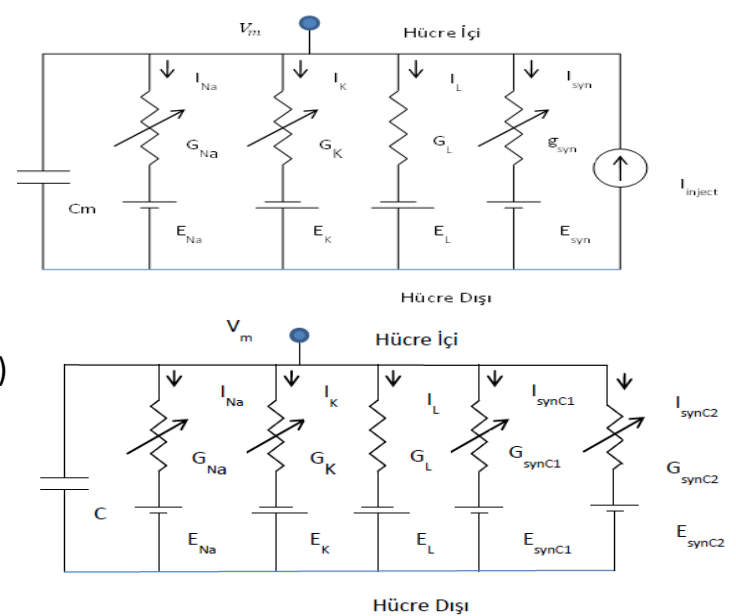

Şekil 1. (a) Harici akım uygulanan hücre modeli (b) Harici akım ve tek sinaptik giriş alan hücre modeli (c) Tek sinaptik giriş alan hücre modeli (d) İki sinaptik giriş alan hücre modeli 


\subsection{Biyolojik ağ yapılarında motif görüntüleri}

Nörolojik, genetik ve besin zinciri gibi birçok biyolojik ağ ortamından yapılan çalışmalar, ağ içerisinde tekrarlı bölümler olduğunu göstermiştir (Helmchen et all., 2018; Gorochowski et all., 2018; Rodrigo et all., 2018; Gal et all., 2018). Şekil 2-a'da farelerin varil korteksinde, iki sinir hücresi arasındaki sinaptik bağlantı gösterilmiştir. Karşılıklı etkileşimli, iki sinir hücresi bağlantısının motif görünümü de şekilde görülmektedir (Feldmeyer et al., 2018). Şekil 2-b'de, farenin beynine ait küçük bölümlerin, elektrotlardan oluşan bir düzenek üzerinde ve özel bir çözelti içinde, tohumlanmasıyla yapılan deneysel kayıtlardan elde edilen ağ yapısı ve içindeki motifler görülmektedir (Dong et al., 2009). (a)

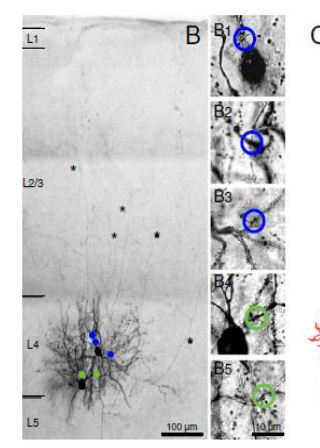

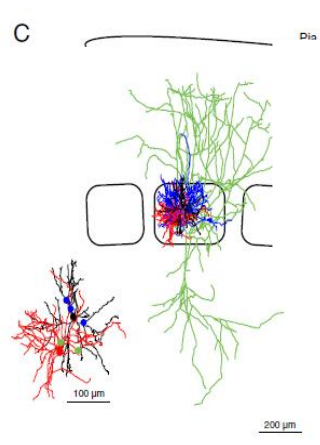

(b)

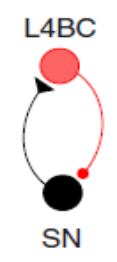

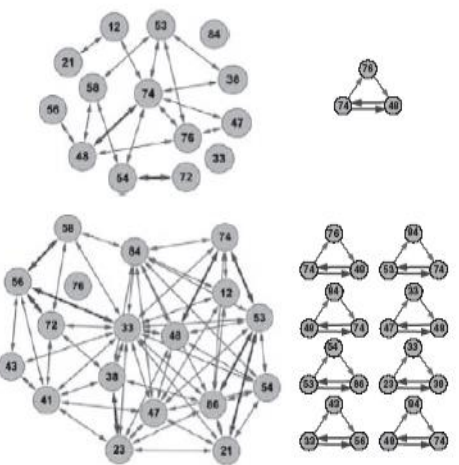

Şekil 2. (a) Fare Varil korteksinin 4. tabakasında hızlı spike ara-sinir hücresi ile ana sinir hücresi çiftinin sinaptik bağlantılarının yapısal oluşumunun biyolojik görüntüsü. Karş1lıklı uyarıcı sinaptik bağlantılar yeşil noktalar ile gösterilmiştir. (b) Fare beynine ait görüntülerde tekrarlanan ăg motifleri

$\mathrm{Bu}$ ve benzeri biyolojik çalışmalarda, birçok tekrarlı bağlantılar görüntülenmiştir. $\mathrm{Bu}$ tekrarlı bölümler, genellikle üç hücreli motif bağlantıları şeklindedir.

\section{3. Çizge (graph) teorisi kullanılarak, tüm üç hücreli motiflerin oluşturulması}

Çizge (graph) teorisi, karmaşık biyolojik sistemleri modellemek için uygulanabilecek matematiksel bir yötemdir. Yöntemde, yapının elemanları; bir çizgenin tepeleri ve aralarındaki etkileşimleri sağlayan kenarlar şeklinde düzenlenmiştir. Çizge algoritması, analiz yapmak, benzeşim yapmak, sistemi gözünde canlandırmak için kullanılmıştır. (Junker and Schreiber, 2008; Sporns, 2018). Motiflerin, uygulanan işaretlere verdikleri tepkilerden, uzun- ve k1sa dönemli bellek davranışının dinamikleri bulunmuştur. Çizgeler şekil 3'de gösterildiği gibi; yönlendirilmemiş, yönlendirilmiş ve karma (miksed) olabilir.
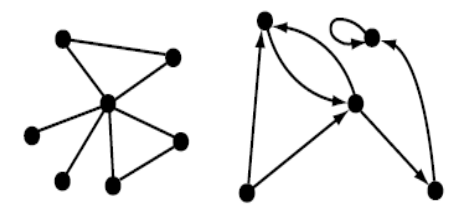

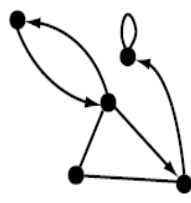

Şekil 3. (a)Yönlendirilmemiş, (b)yönlendirilmiş (c) karmaşık çizge yapısı.

Çalışmalarda, genellikle üç sinir hücresinden oluşan motiflerin, kısa- ve uzun dönem bellek davranışı incelenmiştir (Milo et al., 2002; Bassett and Bullmore, 2006). Üç hücreli yönlendirilmiş tüm motiflerin elde edilmesinde çizge topolojisi kullanılmıştır (Prill et al., 2005; Junker and Schreiber, 2008). Hücrelerin; giriş (A), ara (B) ve çıkış 
(C) olarak değerlendirilmesi çalışmalarda kabul görmüştür ( $\mathrm{Li}, 2008)$.

Üç hücreli, yönlendirilmiş çizge şeklinde oluşturulacak tüm motiflerin elde edilmesi için, (A-giriş, B-ara, C-çıkış rolleri olacak şekilde) tüm motiflerin bitişiklik matrisi, her hücre için aşağıdaki şekilde oluşturuldu. Ardından, elde edilen üç matrisin her bir satırından, bir motifin bağlantı şekli oluşturuldu. Biyolojik sinir ağlarında hücrenin kendisiyle sinaptik bağ kurması söz konusu değildir. Motifler, tablo 1'de görülen bir doğruluk tablosuyla, tümünü kapsayacak şekilde oluşturuldu. Matrislerdeki (1) değeri hücreler arası bağlantı olduğunu, (0) değeri bağlantı olmadığını ifade eder. Bu üç matrisin satırları kullanılarak üç hücrenin birbiriyle yapabileceği muhtemel tüm olasılıklar tablo 1'de gösterildi. Örnek olarak MTF1 isimli motifte; $\mathrm{A}$ hücresinden $\mathrm{C}$ hücresine, $\mathrm{B}$ hücresinden $\mathrm{C}$ hücresine veri iletecek şekilde bir bağlantı vardır. Tabloda (A-C;1, B-C;1) diğerleri sıfir şeklindedir.

$$
\left[A_{\text {bits }}\right]=\left[\begin{array}{ccc}
A & B & C \\
0 & 0 & 0 \\
0 & 0 & 1 \\
0 & 1 & 0 \\
0 & 1 & 1
\end{array}\right] \quad\left[B_{\text {bits }}\right]=\left[\begin{array}{ccc}
A & B & C \\
0 & 0 & 0 \\
0 & 0 & 1 \\
1 & 0 & 0 \\
1 & 0 & 1
\end{array}\right] \quad\left[C_{\text {bits }}\right]=\left[\begin{array}{ccc}
A & B & C \\
0 & 0 & 0 \\
0 & 1 & 0 \\
1 & 0 & 0 \\
1 & 1 & 0
\end{array}\right]
$$

Tablo 1. Üç tepeli çizgelerin tüm bağlantı olasılıkları. (1;bağlantı var 0;bağlantı yok)

\begin{tabular}{|c|c|c|c|c|c|c|c|c|c|c|c|c|c|c|c|c|c|c|c|c|c|c|c|c|c|}
\hline (A) & A & B & C & (B) & A & B & C & (C) & A & B & C & MOTIF & (A) & A & B & C & (B) & A & B & C & (C) & A & B & C & мотіF \\
\hline & 0 & 0 & 0 & & 0 & 0 & 0 & & 0 & 0 & 0 & - & & 0 & 1 & 0 & & 0 & 0 & 0 & & 0 & 0 & 0 & - \\
\hline & 0 & 0 & 0 & & 0 & 0 & 0 & & 0 & 1 & 0 & - & & O & 1 & 0 & & 0 & o & 0 & & 0 & 1 & 0 & - \\
\hline & 0 & 0 & 0 & & 0 & 0 & 0 & & 1 & 0 & 0 & - & & 0 & 1 & 0 & & 0 & 0 & 0 & & 1 & 0 & 0 & - \\
\hline & 0 & 0 & 0 & & 0 & 0 & 0 & & 1 & 1 & 0 & - & & 0 & 1 & 0 & & 0 & 0 & $\overline{0}$ & & 1 & 1 & 0 & - \\
\hline & 0 & 0 & 0 & & 0 & 0 & 1 & & 0 & 0 & 0 & - & & o & 1 & o & & 0 & O & 1 & & o & 0 & 0 & MTF2 \\
\hline & 0 & 0 & O & & 0 & 0 & 1 & & 0 & 1 & 0 & - & & 0 & 1 & 0 & & 0 & O & 1 & & 0 & 1 & 0 & MTF21 \\
\hline & 0 & 0 & 0 & & 0 & 0 & 1 & & 1 & 0 & 0 & - & & 0 & 1 & 0 & & 0 & 0 & 1 & & 1 & 0 & 0 & MTF19 \\
\hline & 0 & 0 & $\mathbf{0}$ & & 0 & 0 & 1 & & 1 & 1 & 0 & - & & 0 & 1 & 0 & & 0 & 0 & 1 & & 1 & 1 & 0 & MTF32 \\
\hline & 0 & 0 & 0 & & 1 & 0 & 0 & & 0 & o & 0 & - & & 0 & 1 & 0 & & 1 & O & 0 & & 0 & O & 0 & - \\
\hline & 0 & 0 & 0 & & 1 & 0 & 0 & & 0 & 1 & 0 & - & & 0 & 1 & 0 & & 1 & 0 & 0 & & 0 & 1 & 0 & - \\
\hline & 0 & 0 & 0 & & 1 & 0 & 0 & & 1 & 0 & 0 & - & & 0 & 1 & 0 & & 1 & 0 & 0 & & 1 & O & o & - \\
\hline & 0 & 0 & 0 & & 1 & 0 & 0 & & 1 & 1 & 0 & - & & 0 & 1 & 0 & & 1 & 0 & 0 & & 1 & 1 & 0 & - \\
\hline & 0 & 0 & 0 & & 1 & 0 & 1 & & 0 & 0 & 0 & - & & 0 & 1 & 0 & & 1 & $\mathbf{0}$ & 1 & & 0 & 0 & 0 & MTF20 \\
\hline & 0 & 0 & 0 & & 1 & 0 & 1 & & 0 & 1 & 0 & - & & 0 & 1 & 0 & & 1 & 0 & 1 & & 0 & 1 & 0 & MTF27 \\
\hline & 0 & 0 & 0 & & 1 & 0 & 1 & & 1 & 0 & 0 & - & & 0 & 1 & $\mathbf{0}$ & & 1 & $\mathbf{0}$ & 1 & & 1 & 0 & 0 & MTF34 \\
\hline & 0 & 0 & 0 & & 1 & 0 & 1 & & 1 & 1 & 0 & - & & 0 & 1 & 0 & & 1 & O & 1 & & 1 & 1 & 0 & MTF33 \\
\hline & 0 & 0 & 1 & & o & 0 & 0 & & 0 & 0 & 0 & TMTF1 & & 0 & 1 & 1 & & 0 & O & 0 & & 0 & 0 & 0 & MTF3 \\
\hline & 0 & 0 & 1 & & 0 & 0 & 0 & & $\mathbf{0}$ & 1 & 0 & MTF25 & & 0 & 1 & 1 & & 0 & 0 & 0 & & 0 & 1 & 0 & MTF23 \\
\hline & 0 & 0 & 1 & & 0 & 0 & 0 & & 1 & 0 & 0 & TMTF2 & & 0 & 1 & 1 & & 0 & 0 & 0 & & 1 & 0 & 0 & MTF24 \\
\hline & 0 & 0 & 1 & & 0 & 0 & 0 & & 1 & 1 & 0 & MTF6 & & 0 & 1 & 1 & & 0 & $\mathbf{0}$ & 0 & & 1 & 1 & 0 & MTF30 \\
\hline & 0 & 0 & 1 & & 0 & o & 1 & & 0 & 0 & 0 & MTF1 & & 0 & 1 & 1 & & 0 & O & 1 & & 0 & 0 & 0 & MTF5 \\
\hline & 0 & 0 & 1 & & o & O & 1 & & 0 & 1 & 0 & MTF22 & & 0 & 1 & 1 & & 0 & 0 & 1 & & 0 & 1 & 0 & MTF8 \\
\hline & 0 & 0 & 1 & & o & O & 1 & & 1 & 0 & 0 & MTF4 & & 0 & 1 & 1 & & 0 & 0 & 1 & & 1 & O & 0 & MTF10 \\
\hline & 0 & 0 & 1 & & 0 & O & 1 & & 1 & 1 & 0 & MTF9 & & 0 & 1 & 1 & & 0 & O & 1 & & 1 & 1 & 0 & MTF28 \\
\hline & 0 & 0 & 1 & & 1 & O & 0 & & 0 & 0 & 0 & MTF18 & & 0 & 1 & 1 & & 1 & $\mathbf{0}$ & 0 & & 0 & $\mathbf{0}$ & 0 & MTF14 \\
\hline & 0 & 0 & 1 & & 1 & $\mathbf{0}$ & 0 & & 0 & 1 & 0 & MTF7 & & 0 & 1 & 1 & & 1 & 0 & 0 & & 0 & 1 & 0 & MTF16 \\
\hline & 0 & 0 & 1 & & 1 & O & 0 & & 1 & o & 0 & MTF26 & & 0 & 1 & 1 & & 1 & $\mathbf{0}$ & 0 & & 1 & o & 0 & MTF15 \\
\hline & 0 & 0 & 1 & & 1 & 0 & 0 & & 1 & 1 & 0 & MTF35 & & 0 & 1 & 1 & & 1 & 0 & 0 & & 1 & 1 & 0 & MTF31 \\
\hline & 0 & 0 & 1 & & 1 & O & 1 & & 0 & 0 & 0 & MTF37 & & 0 & 1 & 1 & & 1 & 0 & 1 & & 0 & 0 & 0 & MTF11 \\
\hline & 0 & 0 & 1 & & 1 & 0 & 1 & & 0 & 1 & 0 & MTF36 & & 0 & 1 & 1 & & 1 & 0 & 1 & & 0 & 1 & 0 & MTF29 \\
\hline & 0 & 0 & 1 & & 1 & $\mathbf{0}$ & 1 & & 1 & $\mathbf{0}$ & 0 & MTF38 & & 0 & 1 & 1 & & 1 & 0 & 1 & & 1 & $\mathbf{0}$ & $\mathbf{0}$ & MTF17 \\
\hline & $\mathbf{0}$ & 0 & 1 & & 1 & $\mathbf{0}$ & 1 & & 1 & 1 & $\mathbf{0}$ & MTF12 & & $\mathbf{0}$ & 1 & 1 & & 1 & $\mathbf{0}$ & 1 & & 1 & 1 & $\mathbf{0}$ & MTF13 \\
\hline
\end{tabular}


Bu işlemin sonucunda 64 ihtimal ortaya çıktı. motifler kısa adlarla isimlendirildi (MoTiF Fakat bunlardan bazıları iki hücreli bazıları ise 1:MTF1, Temel MoTiF 1;TMTF1 gibi) . çıkış rolündeki C hücresine ulaşamadığından Ayrıca motiflerin sinaptik bağlantı yönü okla elendi ((-) işareti koyulanlar). Diğer ve hücre isimleri ile gösterildi (A-B, C-A alternatifler 38 adet olup çalışmamızda gibi).

değerlendirildi. Kolaylık olması açısından

Tablo 2. Üç hücreli tüm motifler.

\begin{tabular}{|c|c|c|c|c|c|c|c|}
\hline $\begin{array}{l}\text { Motif Adı ve } \\
\text { bağlantı şekli }\end{array}$ & $\begin{array}{l}\text { Motif Şekli } \\
\text { (hücrelerin } \\
\text { uyarı yönü) }\end{array}$ & $\begin{array}{l}\text { Motif Adı ve } \\
\text { bağlant şekli }\end{array}$ & $\begin{array}{c}\text { Motif Şekli } \\
\text { (hücrelerin uyarı } \\
\text { yönü) }\end{array}$ & $\begin{array}{l}\text { Motif Adı ve } \\
\text { bağlantı şekli }\end{array}$ & $\begin{array}{l}\text { Motif Şekli } \\
\text { (hücrelerin } \\
\text { uyarı yönü) }\end{array}$ & $\begin{array}{l}\text { Motif Adı ve } \\
\text { bağlantı şekli }\end{array}$ & $\begin{array}{l}\text { Motif Şekli } \\
\text { (hücrelerin } \\
\text { uyarı yönü) }\end{array}$ \\
\hline $\begin{array}{l}\text { MTF1 } \\
\text { B-C, A-C }\end{array}$ & & $\begin{array}{l}\text { MTF2 } \\
\text { A-B, B-C }\end{array}$ & $\mathbf{A}$ & $\begin{array}{l}\text { MTF3 } \\
\text { A-B, A-C }\end{array}$ & & $\begin{array}{l}\text { MTF4 } \\
\text { C-A, A-C } \\
\text { B-C }\end{array}$ & \\
\hline $\begin{array}{l}\text { MTF5 } \\
\text { A-B, A-C } \\
\text { B-C }\end{array}$ & & $\begin{array}{l}\text { MTF6 } \\
\text { C-B, A-C } \\
\text { C-A }\end{array}$ & & $\begin{array}{l}\text { MTF7 } \\
\text { C-B, A-C } \\
\text { B-A }\end{array}$ & & $\begin{array}{l}\text { MTF8 } \\
\text { C-B, A-B } \\
\text { A-C, B-C }\end{array}$ & \\
\hline $\begin{array}{l}\text { MTF9 } \\
\text { C-B, A-C } \\
\text { B-C, C-A }\end{array}$ & & $\begin{array}{l}\text { MTF10 } \\
\text { A-B, A-C } \\
\text { B-C, C-A }\end{array}$ & & $\begin{array}{l}\text { MTF11 } \\
\text { A-B, A-C } \\
\text { B-C, B-A }\end{array}$ & & $\begin{array}{l}\text { MTF12 } \\
\text { C-B, A-C } \\
\text { B-C, C-A, B-A }\end{array}$ & \\
\hline $\begin{array}{l}\text { MTF13 } \\
\text { C-B, A-B, A-C } \\
\text { B-C, C-A, B-A }\end{array}$ & & $\begin{array}{l}\text { MTF14 } \\
\text { A-B, A-C } \\
\text { B-A }\end{array}$ & & $\begin{array}{l}\text { MTF15 } \\
\text { A-B, A-C } \\
\text { C-A, B-A }\end{array}$ & & $\begin{array}{l}\text { MTF16 } \\
\text { C-B, A-B } \\
\text { A-C, B-A }\end{array}$ & \\
\hline $\begin{array}{l}\text { MTF17 } \\
\text { A-B, A-C } \\
\text { B-C, C-A, B-A }\end{array}$ & & $\begin{array}{l}\text { MTF } 18 \\
\text { A-C, B-A }\end{array}$ & & $\begin{array}{l}\text { MTF19 } \\
\text { A-B, B-C } \\
\text { C-A }\end{array}$ & & $\begin{array}{l}\text { MTF20 } \\
\text { A-B, B-C } \\
\text { B-A }\end{array}$ & \\
\hline $\begin{array}{l}\text { MTF21 } \\
\text { C-B, A-B } \\
\text { B-C }\end{array}$ & & $\begin{array}{l}\text { MTF22 } \\
\text { C-B, A-C } \\
\text { B-C }\end{array}$ & & $\begin{array}{l}\text { MTF23 } \\
\text { C-B, A-B } \\
\text { A-C }\end{array}$ & & $\begin{array}{l}\text { MTF24 } \\
\text { A-B, A-C } \\
\text { C-A }\end{array}$ & \\
\hline $\begin{array}{l}\text { MTF25 } \\
\text { C-B, A-C }\end{array}$ & & $\begin{array}{l}\text { MTF26 } \\
\text { A-C, B-A } \\
\text { C-A }\end{array}$ & & $\begin{array}{l}\text { MTF27 } \\
\text { C-B, A-B } \\
\text { B-C, B-A }\end{array}$ & & $\begin{array}{l}\text { MTF28 } \\
\text { C-B, A-B } \\
\text { A-C, B-C, C-A }\end{array}$ & \\
\hline $\begin{array}{l}\text { MTF29 } \\
\text { C-B, A-B } \\
\text { A-C, B-C, B-A }\end{array}$ & & $\begin{array}{l}\text { MTF30 } \\
\text { C-B, A-B } \\
\text { A-C, C-A }\end{array}$ & & $\begin{array}{l}\text { MTF31 } \\
\text { C-B, A-B } \\
\text { A-C, C-A, B- } \\
\text { A }\end{array}$ & & $\begin{array}{l}\text { MTF32 } \\
\text { C-B, A-B } \\
\text { B-C, C-A }\end{array}$ & \\
\hline
\end{tabular}




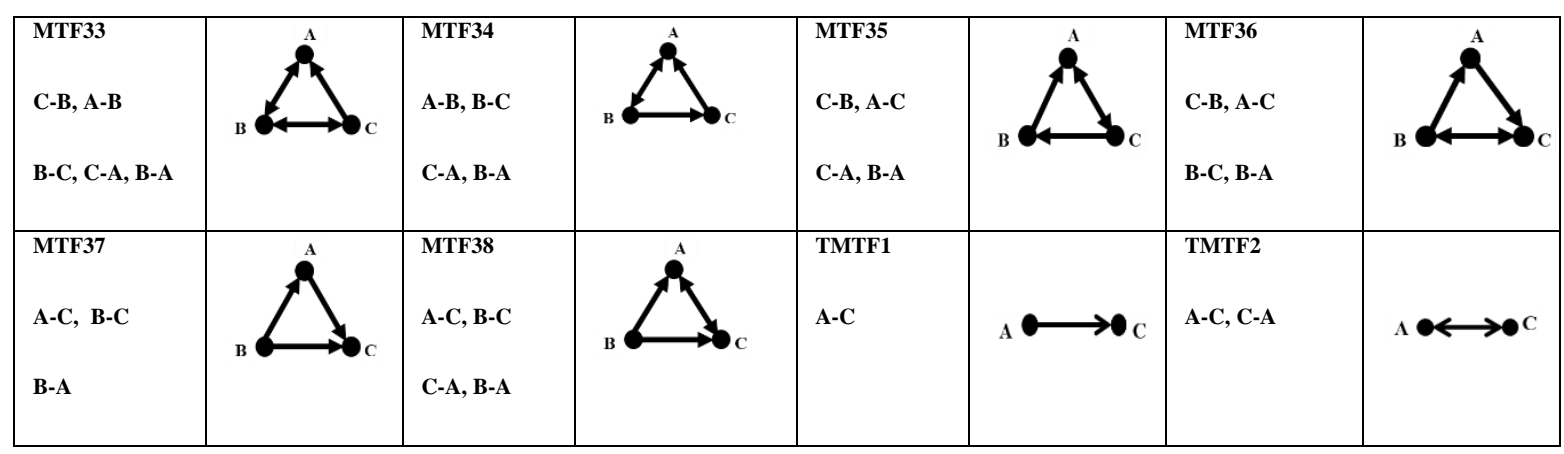

\subsection{Kısa-ve uzun dönem bellek yapısı}

Düşünmenin çoğunun ve bilgi işlemenin gerçekleştiği kısa-dönem bellek, belleğimizin en fazla iş gören bölümü olarak kabul edilmektedir. Kısa-dönem belleğe gelen bilgi için üç alternatif bulunmaktadır. Ya bilgi ihmal edilir (unutulur), ya tekrar edilerek kısa dönem bellekte tutulur, ya da tekrarlama ile daha önceki bilgilerle birleştirilerek, uzun süreli belleğe transfer edilir. (Keleş and Çepni 2006). Yapılan çalışmalarda; kısa-dönem belleklerin farklı tipleri, oluşumları, iç etkenlerin ve sinaptik yapının etkisinin nasıl olduğu ve bu yapıların uzun-dönem belleğe zamansal akış açısından nasıl dönüştürüldüğü araştırılmaktadır (Arbib, 2003).

Bir bilginin uzun-dönem belleğe yerleştirilebilmesi için, sık sık tekrar edilmesi gerekmektedir. Uzun-dönem bellekte, sözcükler, genellikle işitildikleri sesleriyle birlikte değil, taşıdıkları anlamları ile saklanmaktadır. Uzun -dönem bellekte, ses, koku ve görüntülerin saklanması mümkündür. Bir bilginin uzundönem bellekte saklanması, ancak beynimizdeki nöral bağlantılarda meydana gelen, kalıcı, fonksiyonel, biyokimyasal ve yapısal değişikliklerle mümkün olabilmektedir (Keleş and Çepni 2006).

\section{Bulgular}

Bu çalışmada, üç hücreli tüm motifler üzerinde çeşitli uygulamalar yapıldı. Hücrelerin birbirlerini karşılıklı uyarma durumları, bir hücrenin birden çok uyarı alma durumu, motiflerde hücrelerin birbirlerini (E veya I) uyarma şekillerinin değişken olması durumlarında, uzun- ve kısa dönem bellek davranış1 gösterdiği durumlar incelendi. Motifler değerlendirilirken, özellikle hücre uyarı türleri değiştirilerek, kısa- ve uzun dönem bellek davranışı incelendi.

\subsection{Motif temel bağlantılarının, hücre uyarım türü çalışmaları}

Tablo 2'de TMTF2 isimli, karş1lıklı etkileşimli iki sinir hücresi bağlantısı, birçok motif yapısı içinde vardır. Bu bağlantıdaki iki hücrenin elektriksel modeli, şekil 1-b ve şekil 1-c'de gösterilmişti. Bu modellerde; A hücresi hem harici akım, hem de $\mathrm{B}$ hücresi tarafından uyarılmaktadır. B hücresi ise sadece A hücresi tarafından uyarılmaktadır. Şekil 4(a)'da görülen ve hücreye detritlerden gelen toplam akımı ifade eden, düzgün dağılımlı rastlantısal akım, A hücresine uygulandı. A hücresinde, harici akım uyarımına bağlı aksiyon potansiyeli oluştuğunda, B hücresinde denklem18' de görülen zaman bağımlı $g_{\text {synB }}$ iletkenliği aktif oldu. Eğer uyarım türü (uyarıcı-E) ise B hücresinde de aksiyon potansiyeli oluştu. Oluşan bu etkiyle, A hücresinde $g_{\text {syna }}$ aktif oldu ve uyarım türü (uyarıcı-E) ise A hücresinde üretilen aksiyon potansiyeli desteklendi. A hücresine yapılan uyarı kesilse de, hücreler arası karşılıklı bağlantıdan dolayı, şekil 4 (b)'de görüldüğü gibi, $A$ ve $B$ hücrelerinde sürekli aksiyon potansiyellerinin üretilmeye devam ettiği görüldü. 
(a)

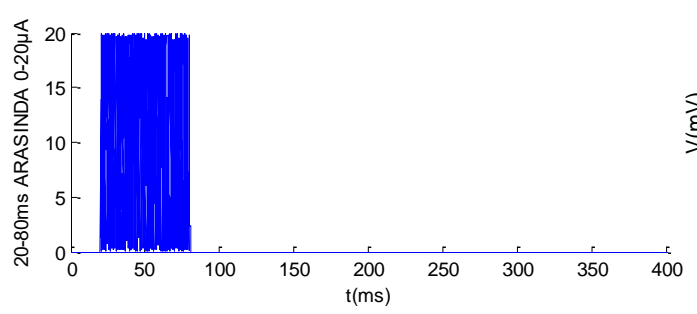

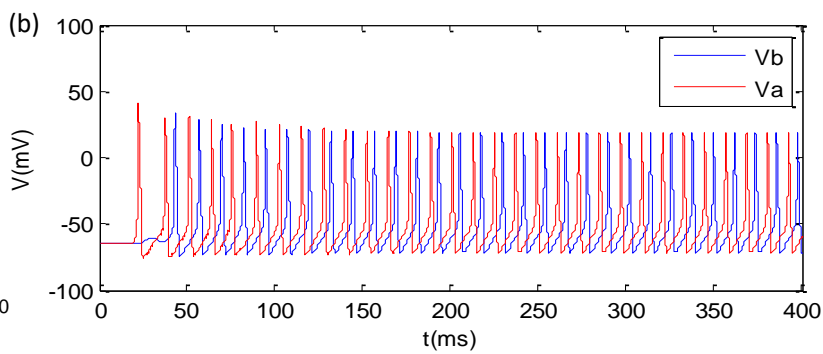

Şekil 4. Tablo 1'deki TMTF2'de; (a) A hücresine (Şekil 1-b'de hücre modeli) uygulanan $20 \mu A$ düzgün dağılımlı rastlantısal akım, (b) hücrelerin uyarım şekli (EE) olduğunda $\mathrm{A}$ ve $\mathrm{B}$ hücrelerinde oluşan aksiyon potansiyelleri

Şekil 4(b)'de görülen bu durum, öğrenme uyarısı kesilse de, bilginin bellekte tutulmaya devam ettiği, uzun-dönem bellek davranışının bir örneğidir. Uyarım şekli (AB veya BA-EI) olduğunda uyarım akımı kesilince hücrelerde de aksiyon potansiyeli sona erdi. Uyarım (IE) ve (II) olduğunda ise B hücresinde aksiyon potansiyeli üretilmemiştir.

Tablo 2'de görülen MTF1 isimli motifte, birçok motif yapısında görülmektedir. $\mathrm{Bu}$ bağlantıda $\mathrm{C}$ hücresi birden çok uyarı alır. $\mathrm{C}$ hücresinin elektriksel modeli şekil 1(d)'de gösterilmişti. $\mathrm{Bu}$ çalışmada, bir hücreye birden çok uyarı gelme durumunu modellemek için; A ve B hücresine yapılan harici akım uyarılarının etkisiyle, C

(a)

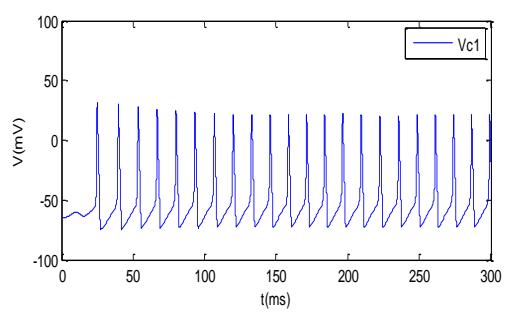

(b)

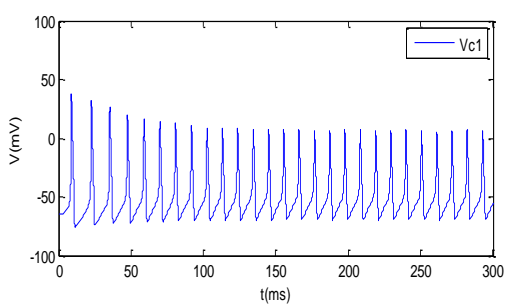

(c)

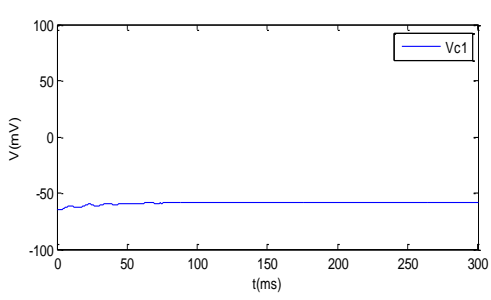

Şekil 5. MTF1 motifinde, harici 10 $\mu A^{\prime}$ lik DC akım (a) sadece A hücresine (b) A ve B hücresine (uyarım, AB-EE) (c) A ve B hücresine (uyarım, AB-EE), uygulandığında, C hücresinde oluşan aksiyon potansiyelleri. 
3.2. Kısa- ve uzun dönem bellek davranışı gösteren üç hücreli motiflerin belirlenmesi

Motif bileşenleri üzerinde yapılan çalışmalardan sonra, tablo 2'de gösterilmiș olan tüm motifler, kısa-ve uzun dönem bellek davranışı gösterdiği durumlar açısından incelendi. Bu amaçla, motifler üzerinde yapılan çalışmalara örnek olması için, tablo 2'de görülen MTF8 motifi üzerindeki çalışmalar bu bölümde gösterildi. Şekil 4(a)'da akım rastlantısal olduğundan, aksiyon potansiyeli oluşturma büyüklügü her seferinde farklı zaman değerlerinde oluşmaktadır. $\mathrm{Bu}$ nedenle MTF8 motifinde, A hücresine bu akım $50 \mathrm{kez}$ uygulandı (uyarım ABC-EEE). Şekil 6(a)'da

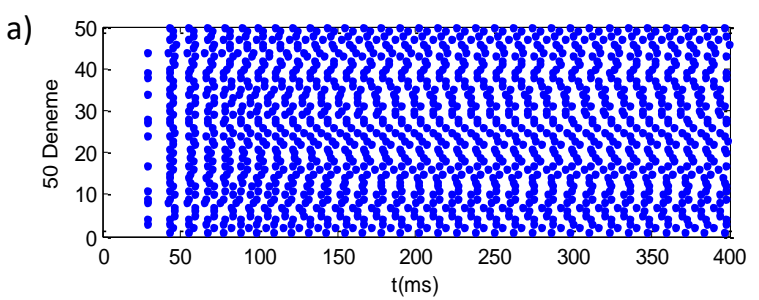

görüldüğü gibi, A hücresine yapılan uyarı kesildikten sonra, C hücresinde sonsuz aksiyon potansiyelleri üretildi. Böylece motif uzun-dönem bellek davranışı gösterdi. Aynı motifte uyarım (ABC-EEI) yapıldığında, şekil 6(b)'de görüldüğg̈ gibi, A hücresine yapılan harici akım uyarısı bittikten sonra yaklaşık $60 \mathrm{~ms}$ süreyle $\mathrm{C}$ hücresinde aksiyon potansiyelleri üretilmeye devam etti. Böylece motif bilgi öğretimi bittikten sonra, bilginin bir süre tutulup unutulması şeklinde davranan, kısadönem bellek davranışı göstermiş oldu. Burada uyarı türünün değişimi ile aynı motifin hem uzun hem de kısa dönem bellek davranışı sergilediği gösterildi. (Şekil 6'daki grafik türü kısa- ve uzun dönem bellek davranışını göstermek için kullanılır.)

b)

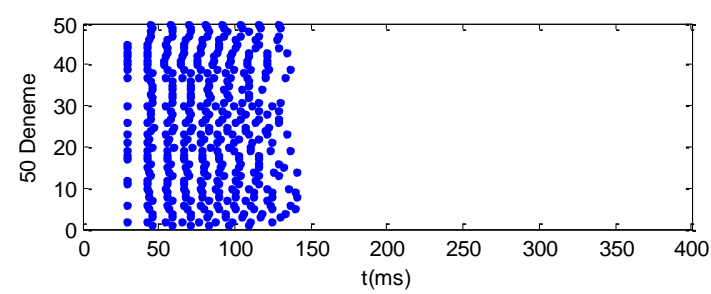

Şekil 6. MTF8 motifinde A hücresine, şekil 4(a)'da görülen akım uygulandığında, (a) uyarım (ABC-EEE) olduğunda, (b) uyarım (ABC-EEI) olduğunda; 50 deneyden her birinde $\mathrm{C}$ hücresinde oluşan aksiyon potansiyellerinin zamanları.

Tablo 2'de görülen ve çizge topolojisi uygulandı. Her motif, hücre bağlantılarına kullanılarak, biyolojik ağ ortamındaki motif uygun olarak, hücreleri arasındaki uyarım oluşumuna uygun olarak oluşturulan tüm durumlarının (E,I) tüm olasılıkları için motiflere, yukarıda anlatılan çalışmalar yukarıdaki çalışma gibi incelendi.

Tablo 3. Uzun dönem bellek davranış1 gösteren üç hücreli motifler.

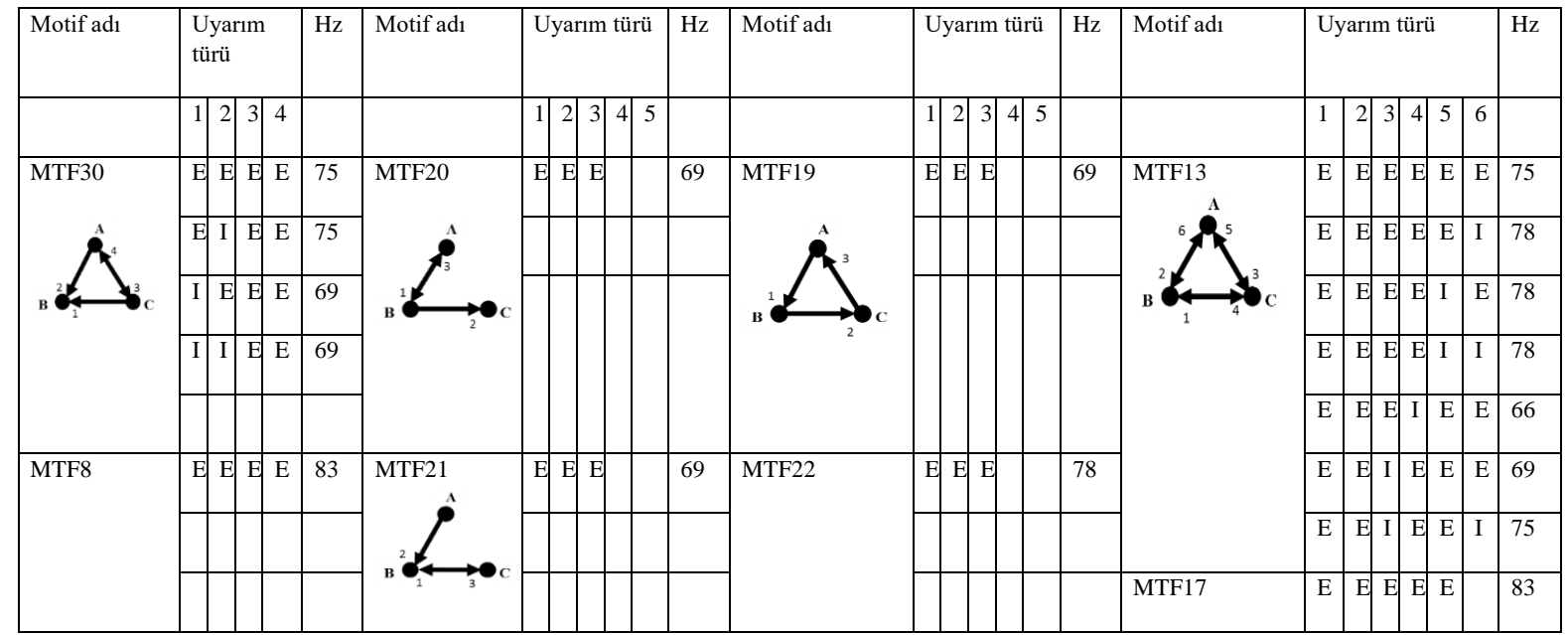




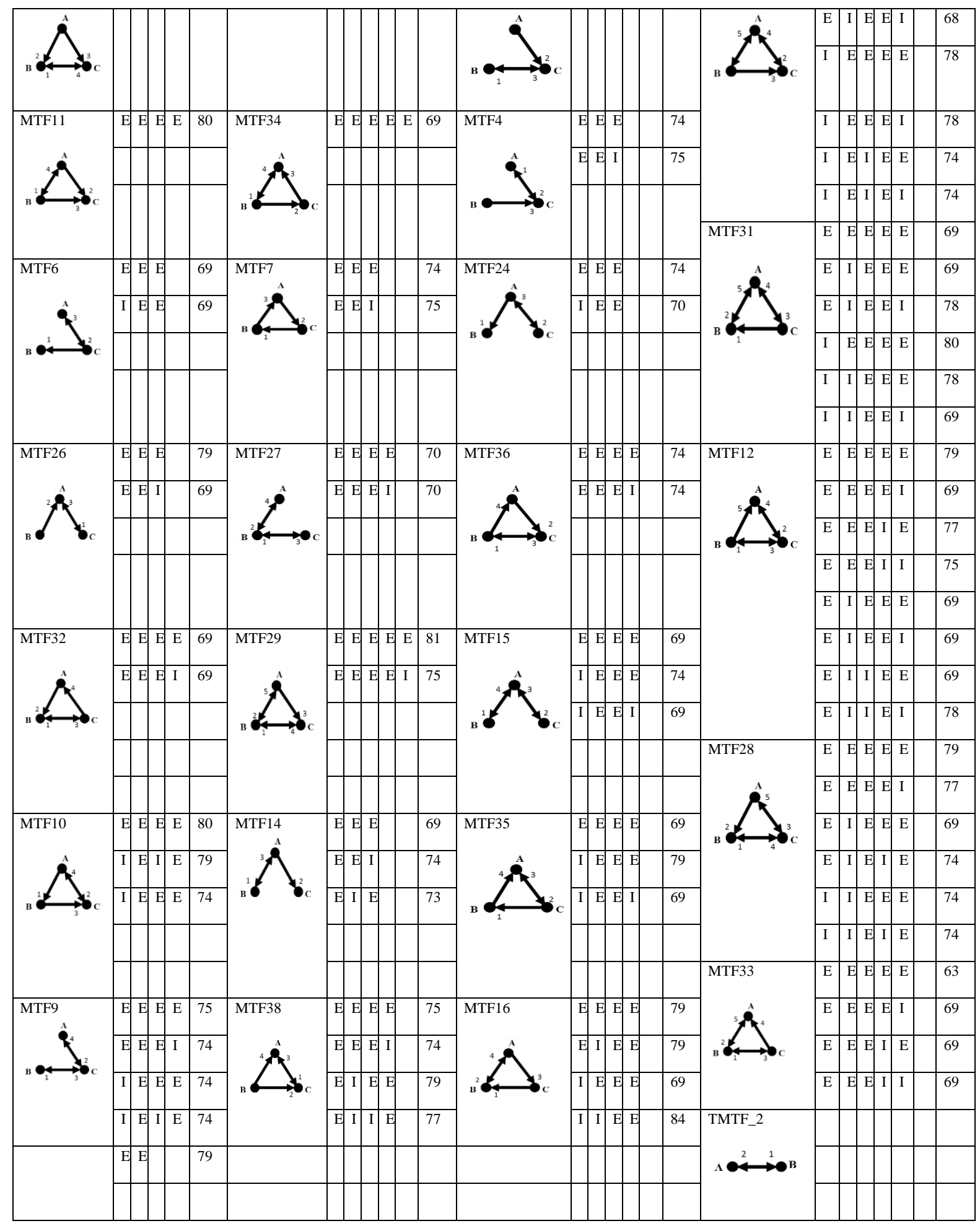

Yapılan çalışmalarda, motiflerin uyarım türüne bağlı olarak, kısa -ve uzun dönem bellek davranışı gösterdiği durumlar belirlendi. Tablo 3'de gösterilen motiflerin, yanlarında belirtilen uyarım durumlarında, uzun dönem bellek davranışı gösterdikleri belirlendi. Diğer durumlarda, bellek özelliği göstermediler veya kısa dönem bellek özelliği gösterdiler. Uzun dönem bellek davranışı gösteren motiflerin ortak özelliklerinin, üç hücre bağlantısında, C hücresini içine alan bir döngünün olduğu belirlendi (A-BC, AB-C veya $\mathrm{ABC}$ ). Tablo 3'de, motif bağlantısındaki okların yanında görülen rakamlar, motifin sağ 
tarafinda, uyarım türünün hangisi olduğunu belirlemek için kullanıldı. Her uyarım durumu için, $\mathrm{C}$ hücresinde oluşan sinyalin frekansı yazıldı. C hücresine birden çok uyarım durumunda, uyarım durumuna bağlı olarak frekansin arttı̆̆ görüldü. Böylece tüm üç hücreli motiflerden uzun dönem bellek davranışı gösterenler, uyarım durumlarıly birlikte belirtildi.

Tablo 4'de, kısa dönem bellek özelliği gösteren motifler gösterildi. Tablo 1'deki motiflerde, hücrelerin birbirlerini uyarım türlerinin (E,I) tüm olasılıklarında, yukarıdaki çalı̧̧ma tekrarlandı. A hücresine yapılan uyarim kesildikten sonra, aksiyon potansiyellerinin bir süre daha devam ettiği gözlendi. Hücrelere, şekil 2'daki akım uyarımında, 3 aksiyon potansiyeli oluşmaktadır. Akım uyarımının kesilmesinden sonra, 5 aksiyon potansiyeli üreten durumlar kısa dönem bellek olarak değerlendirildi. $\mathrm{Bu}$ sürenin değişimi ayrı bir çalı̧̧ma konusudur.

Tablo 4. Kısa dönem bellek davranışı gösteren üç hücreli motifler.

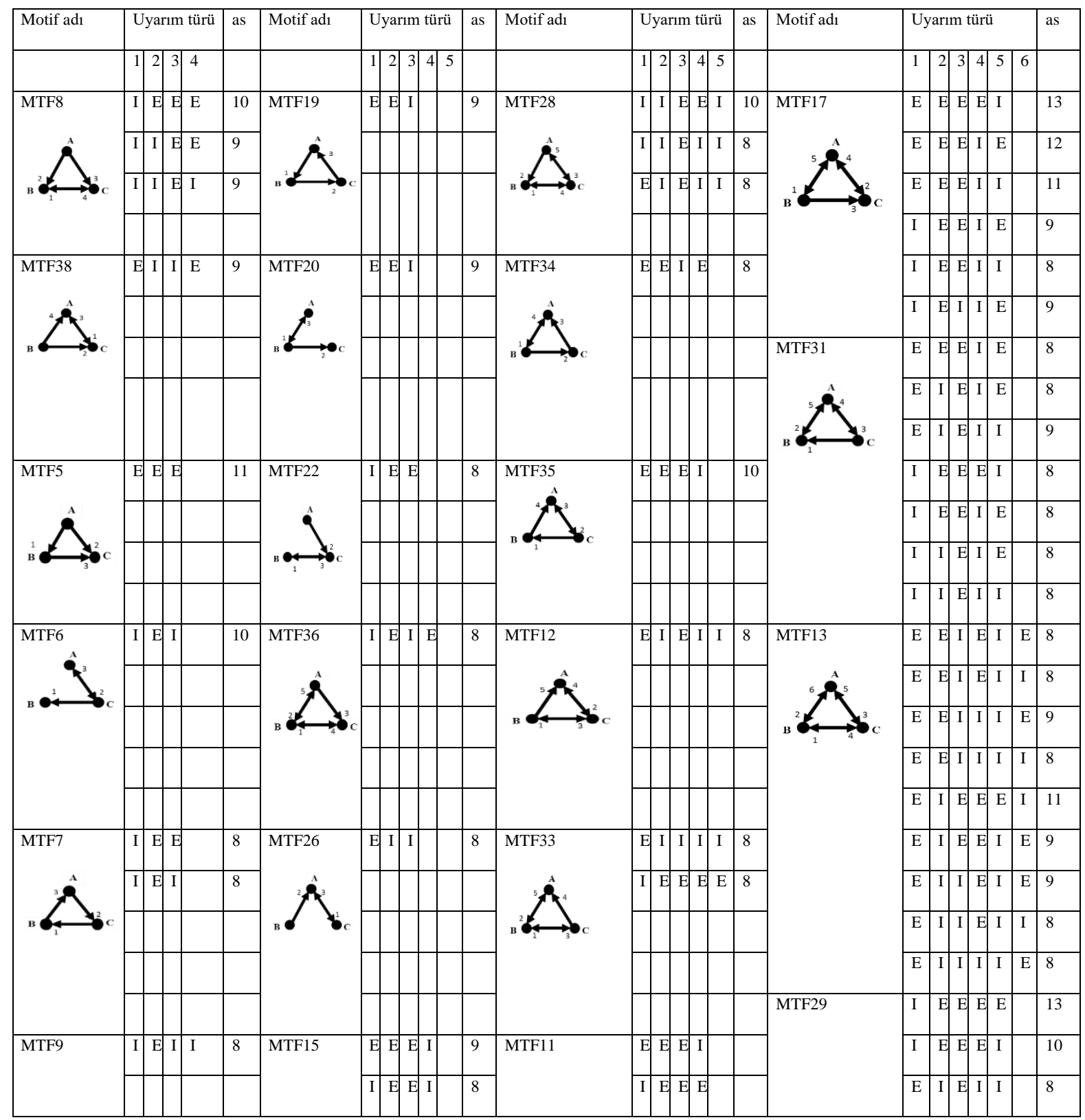




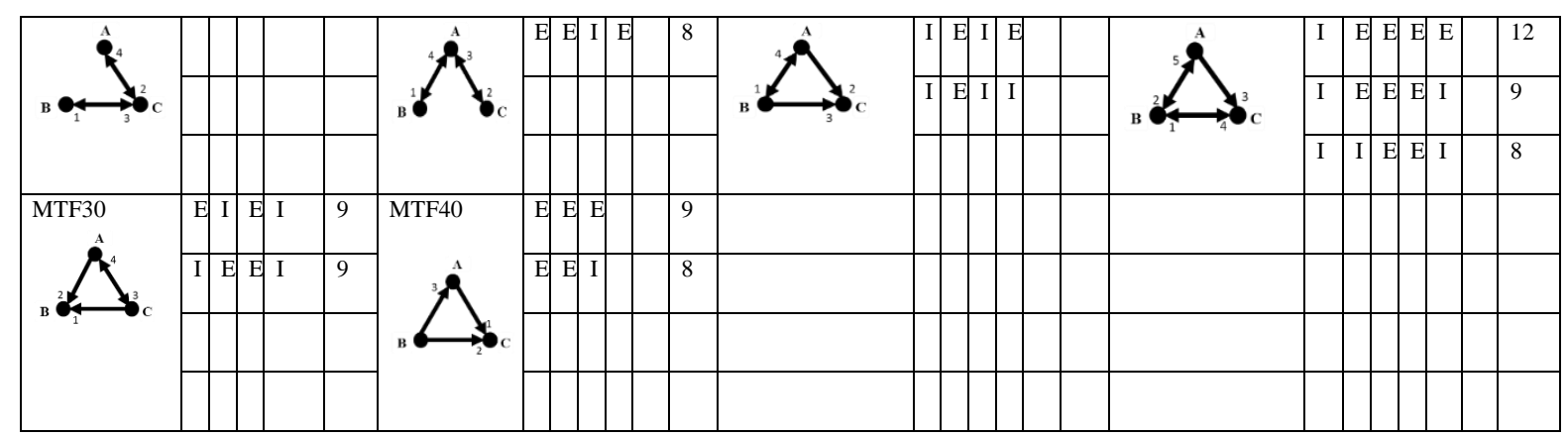

$\mathrm{Bu}$ çalışmayla, tüm üç hücreli motiflerden kısa dönem bellek davranışı gösterenler, uyarım durumlarıyla birlikte belirlendi. Bazı motiflerin hem uzun, hem de kısa dönem bellek davranışı göstermeleri, uyarı türü değişikliğinin bu konuda çok önemli olduğunu göstermiş oldu.

\section{Sonuç}

$\mathrm{Bu}$ çalışmada, biyolojik bellek yapısında olabilecek tüm üç hücreli motifler, çizge topolojisi kullanılarak sistematik bir şekilde elde edildi. Bu motiflerden ağ yapısına uygun 38 adet motif üzerinde yapılan çalışmalardan elde edilen bulgular değerlendirildi. Literatürdeki çalışmalardan farklı olarak, motifler belirlenirken, motifi oluşturun üç hücrenin farklı rolleri dikkate alındı. Hodgkin-Huxley hücre modeliyle oluşturulan, tüm üç hücreli ağ motiflerinin bellek davranışı, tüm uyarı olasılıkları için kapsamlı incelendi. Motiflerin, uzun -ve kısa dönem bellek davran1şının, hücrelerin uyarıcı (E) veya engelleyici (I) uyarımına ve motifin yapısına bağlı olduğu gösterildi. Hangi motiflerin hangi şartlarda bu davranışları sergiledikleri tespit edilerek sınıflandırıldı. Böylece, bilginin biyolojik ağlarda hangi şartlarda saklandığı konusunda, kapsamlı bir çalışma yapılmış oldu. $\mathrm{Bu}$ motiflerin tespitinden sonra, uygun motifler üzerine odaklanarak, öğrenme konusunda daha belirleyici çalışmalar yapılabilir.

\section{Kaynaklar}

Arbib, M.A., (2003). "The handbook of brain theory and neural network" Second edition.

Bassett, D.S. \& Bullmore E., (2006). "Smallworld brain networks" Neuroscientist, 512523.

Bassett, D.S. \& Bullmore E., (2017). "SmallWorld Brain Networks Revisited" The Neuroscientist. Vol. 23(5) 499-516 (C) DOI: $10.1177 / 1073858416667720$

journals.sagepub. com/ home/nro

Bower, J.M. \& Beeman, D., (1998). "The Book of GENESIS" Second edition. SpringerVerlag, New York

Cornelia, I.B. \& Eve, M., (2013). "From the connectome to brain function" Nature America.

Dayan, P. \& Abbott, L.F., (2002). "Theoretical neuroscience" file:///E//Media_folder/Books/

books.pdox.net/

Physics/Theoretical_Neuroscience/TOC.htm.

Feldmeyer, D., Qi, G., Emmenegger, V., \& Staiger, J.F., "Inhibitory Interneurons and their Circuit Motifs in the Many Layers of the Barrel Cortex" Neuroscience 368 (2018) 132-151

Dong, C.Y., Lim, J., Nam, Y. \& Cho, K.H., (2009). "Systematic analysis of synchronized oscillatory neuronal networks reveals an enrichment for coupled direct and indirect feedback motifs" Bioinformatics, 25, 13, 1680-1685. 
Feldmeyer, D., Qi, G., Emmenegger, V. \& Staiger, J.F., (2018). "Inhibitory Interneurons and their Circuit Motifs in the Many Layers of the Barrel Cortex" Neuroscience 368, 132151

Gal, E., London M., Globerson A., Ramaswamy S., Reimann M.,W., Muller E., Markram H., \& Segev I., (2017). "Rich celltype-specific network topology in neocortical Microcircuitry" doi:10.1038/nn.4576

Gerstner, W. \& Kistler, W.M., (2002). "Spiking neuron models". Cambridge University Press.

Gorochowski, T.E., Grierson, C.S., Bernardo M., (2018). "Organization of feed-forward loop motifs reveals architectural principles in natural and engineered networks" Sci. Adv., eaap9751

Heinz, K., \& Stefan, H., (2009). "Motifs, algebraic connectivity and computational performance of two data-based cortical circuit templates" International Workshop on Computational Systems Biology.

Helmchen, F., Gilad A. \& Chen, J.L., (2018). "Neocortical Dynamics During WhiskerBased Sensory Discrimination in HeadRestrained Mice" Neuroscience 368, 57-69

Humphries M. D., (2017). "Dynamical networks: Finding, measuring, and tracking neural population activity" Massachusetts Institute of Technology Published under a Creative Commons Attribution 4.0 International (CC BY 4.0) license, Cilt 1 | Say1 4 | 2017 s.324-338, December 31, 2017

Izhikevich, E.M., (2007). "Dynamical systems in neuroscience" The MIT Press Cambridge, London. 16-17

Jackman S.L., Regehr W.G., (2017). "The Mechanisms and Functions of Synaptic Facilitation". https://doi.org/10.1016/ j.neuron.2017.02.047,Volume 94, Issue 3, Pages 447-464
Junker, B.H. \& Schreiber, F., (2008). "Analysis of biological networks"

Kaiser, T.F. \& Peters, F.J., (2009). "Synaptic Plasticity" Nova science publishers, New York.

Keener J. \& Sneyd, J., (2009). "Mathematical physiology". Second Edition.

Keleş E. \& Çepni S. (2006). "Beyin ve Öğrenme". Journal of Turkish Science.

Kim, J.R., Yoon, Y. \& Cho, K.H., (2008). "Coupled feedback loops form dynamic motifs of cellular networks" Biophysical Journal 94, 359-365.

Li, C., (2008). "Functions of neuronal network motifs" physical reviewe E 78(3 PT 2):037101

Meng, L. \& Xiang, J. (2018) "Brain Network Analysis and Classification Based on Convolutional Neural Network", Front Comput Neurosci. doi: 10.3389/fncom.2018.00095

Milo, R., Shen, O.S., Itzkovitz, S., Kashtan, N., Chklovskii, D., \& Alon, U., (2002). "Network motifs simple building blocks of complex networks" Science. 298, 824-827.

Navlakha S., Joseph Z.B. \& Barth A.L., (2018). "Network Design and the Brain" https://doi.org/10.1016/ j.tics.2017.09.012 , Volume 22, Issue 1, Pages 64-78

Prill, R.J, Iglesias, P.A., \& Levchenko, A., (2005). "Dynamic properties of network motifs contribute to biological network organization" Plos Biol.

Rodrigo, C.J., G., Jaramillo, A. \& Elena S.F., (2009). "Reverse-engineering the Arabidopsis thaliana transcriptional network under changing environmental conditions" Genome Biology 10:R96 (doi:10.1186/gb-2009-10-9r96)

Schachinger, D., (2003). "Simulation of extracellularly recorded activities from small 
nerve formations in the brain" Thesis, Wien, Mai.

Song, S., Sjöström, P.J., Reigl, M., Nelson, S., \& Chklovskii, D.B., (2005) "Highly nonrandom features of synaptic connectivity in local cortical circuits"

Sporns, O. \& Kotter, R., (2004). "Motifs in Brain Networks". PLoS Biol.

Sporns, O., (2018) "Graph theory methods: applications in brain networks", Dialogues Clin Neurosci. 20(2): 111-121.

Wang, J., Jianming, G.J., \& Fei, X., (2005). "Two-parameters hopf bifurcation in the Hodgkin-Huxley model” 23, 973-980. 